\title{
Tolerance: The World of Yang Fudong
}

\author{
Claire Roberts
}

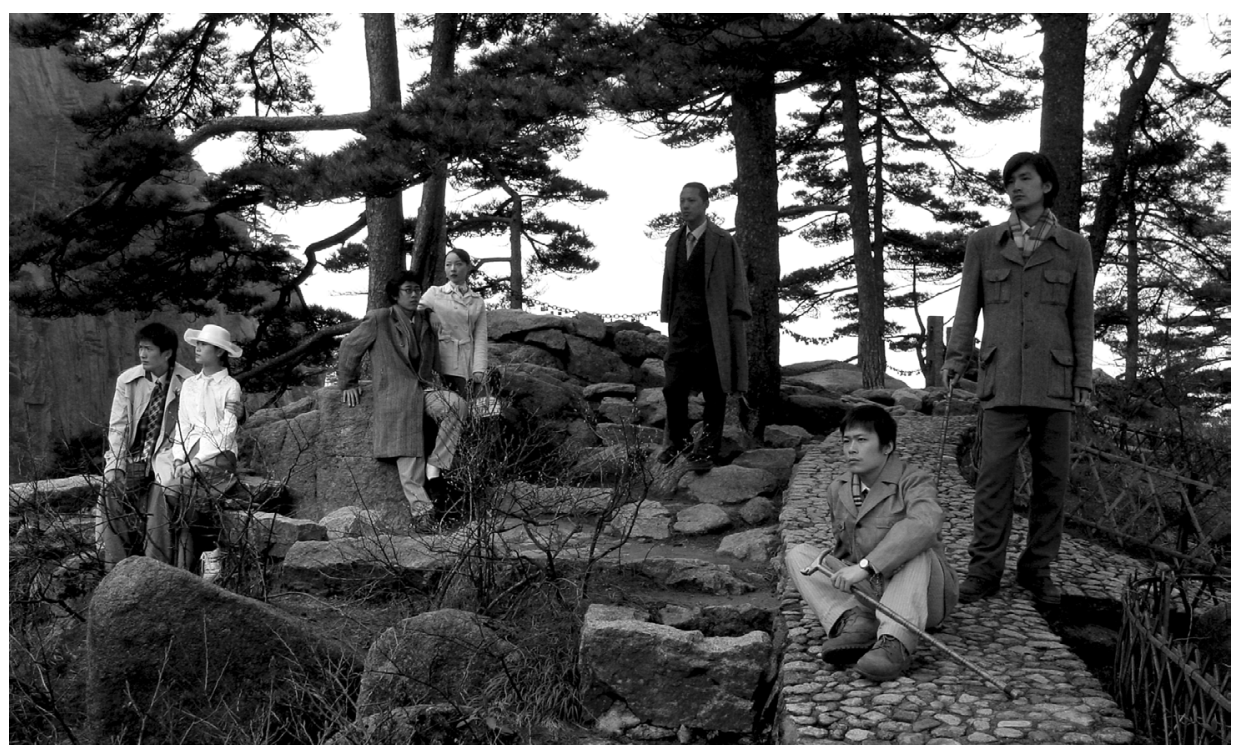

\section{Yang Fudong, 2003, Seven Intellectuals in Bamboo Forest, Part I, Photograph B\&W C-Print, 120 x $180 \mathrm{~cm}$. Edition of 10.}

Courtesy of Artist Yang Fudong and ShanghART Gallery

In an essay titled 'Poetry and Painting' Simon Leys discusses the Chinese scholarly art of brush-and-ink painting, a practice in which calligraphic mark making, the careful balancing of ink brush strokes and areas of void, or darkness and light, is understood as an act that resonates with the dynamism of cosmic creation. ${ }^{1}$ A painting, and in particular a landscape painting, is said to represent a microcosm of the universe. Leys refers to China as 'an organic entity' in which every element can be understood only in relation to others and identifies harmony as the key concept of Chinese civilisation. He elaborates: 'China is a world.... More exactly, one should say that China is a certain world view, a way of conceiving the relations between man and the universe-a recipe for the cosmic order'. Learning about Chinese civilisation, he says, requires a 'global intuition'. '

\footnotetext{
1 Leys, S. 1985, 'Poetry and Painting: Aspects of Chinese Classical Aesthetics', in S. Leys, The Burning Forest, New York, Henry Holt and Company, pp. 3-34. Simon Leys is the pen name of Pierre Ryckmans.

2 Leys, 'Poetry and Painting', pp. 4-5.
} 
While Leys' writing is directed at what we might think of as traditional Chinese aesthetics and a traditional Chinese world view, the idea of China as a world, or representing a certain world view, retains some validity today. This is particularly the case in relation to the difficulty of comprehending the complexity of contemporary Chinese society with its historic overlays of Confucianism, Daoism, Buddhism, Republicanism, Communism and state capitalism. ${ }^{3}$ Today Chinese artists live and work in a globalised world of a kind that was impossible to imagine 30 years ago, a unique mix of Communist control and free-wheeling economics. Chinese experimental art reflects world trends. Many artists use photography and video, media that directly reference and at the same time question reality, to give expression to ideas and emotions, and mediate the world that they inhabit.

During a series of interviews with Shanghai-based artist Yang Fudong (b. 1971), conducted in 2010-11 for the Sherman Contemporary Art Foundation exhibition 'No Snow on the Broken Bridge', Yang Fudong posed the questions 'What is reality?', and 'What is the reality in your mind?'. His questions point to the significance of perspective in creative practice and a dichotomy between state or collective and individual perceptions of what constitutes reality. ${ }^{4}$ In the course of the interviews Yang Fudong repeatedly used words like 'beauty' (mei; meihao; meide ganjue), and 'sensation' or 'feeling' (ganjue). ${ }^{5}$ Of particular interest was the way he described his practice in relation to China and the world. Yang used the metaphor of the ocean, made up of water, which he described as a medium that moves around, and cannot be fixed or precisely identified as belonging to one place or another, while also pointing out the paradox of operating in an expansive globalised world, and yet living and working in a relatively small, circumscribed and culturally familiar environment. ${ }^{6}$

\footnotetext{
3 Since 2005 the concept of harmony (hexie), a universalist philosophical idea central to Confucian and Daoist conceptions of the world, has been employed in the slogan 'harmonious society' (hexie shehui) and been used as a narrative device to assist the Chinese Communist Party maintain social stability and enhance its image and strategic direction. Related to China's rise as the world's second largest economy, is the Chinese government's ongoing efforts (launched at the Beijing Olympics) to present its own narrative of Chinese history to its citizens and the world, 'The China Story'. Endeavours such as The Australian Centre on China in the World's China Story yearbooks, are part of an ongoing effort by scholars working outside China to understand and interpret the 'China Story', from official and non-official perspectives. See 'Building harmonious society crucial for China's progress: Hu'. http://english.peopledaily.com.cn/200506/27/eng20050627_192495.html (viewed 11 January 2013); and Barmé, G. R. 2012, Red Rising, Red Eclipse, Australian Centre on China on the World, The Australian National University, http://www.thechinastory.org/yearbooks/yearbook-2012/coverand-introduction/ (viewed 11 January 2013).

4 Li Zhenhua interview with Yang Fudong, 2011, 'Do Human Beings Have A Spiritual Life?', The Distance of Reality: Solo Exhibition of Yang Fudong, exh. cat. Havana, Wifredo Lam Contemporary Art Center, pp. 168, 180. 5 An interview with Yang Fudong was conducted in Shanghai on 28 November 2010 with a follow-up phone interview on 14 January 2011.

6 Roberts, C. 2011, 'No Snow on the Broken Bridge: An Interview With Yang Fudong', in Yang Fudong: No Snow on the Broken Bridge, exh. cat., Sydney, Sherman Contemporary Art Foundation, p. 26.
} 
Like many of his contemporaries Yang Fudong regards himself as an artist rather than a Chinese artist. He has ready access to information about contemporary art from around the world and chooses to live and work in China rather than sojourn abroad as was the case with an earlier generation. China is his reality. The artistic language of photography and video allows him to construct worlds that appear real but are the product of his mind, connecting him with cosmopolitan ideas: '...you respect and trust the moment in which you live and what you have. And you continue working according to your own thoughts and beliefs'. 'If you want to move forward', he said, 'you need to be someone who is of the world...you need to maintain an interested state of mind.. Talking with friends, it seems that these past few years we have given more thought to the concept of tolerance (kuanrong) ... By this I mean tolerance in relation to people, art and life'.

Yang Fudong went on to say:

The idea of tolerance also relates to feelings. Some of us have interpreted this as maintaining belief in the ultimate importance of knowledge. There are so many things that one does not understand. You cannot say that, just because you don't understand something, it is no good or uninteresting. Rather, it is that you don't yet have the knowledge ...We are often functioning in a state of ignorance...In this context, tolerance includes an element of self-awareness. ${ }^{7}$

In discussing the creative world of Yang Fudong consideration will be given to the notion of artistic reality, and the significance of the phrase kuanrong. ${ }^{8}$ In English 'tolerance' means the disposition to be patient with or indulgent to the opinions or practices of others; freedom from bigotry or undue severity in judging the conduct of others; forbearance. The Chinese word kuanrong literally means 'broad-faced' or to be 'broad and accepting' and is imbued with particular cultural and political resonances.

The way that in recent years the concept of tolerance (kuanrong) has figured in the consciousness of Yang Fudong and his friends is a result, in part, of their knowledge of world affairs gleaned from international travel and the internet. It may also relate to discussions within China of the need to create a civil society and resignation to the fact that institutional and structural change may not happen any time soon. The Chinese word for tolerance, kuanrong, is complex. It means forbearance, but can also suggest leniency or magnanimity, to forgive, to pardon, to excuse.

7 Claire Roberts interview with Yang Fudong, 28 November 2010.

8 With thanks to the two anonymous reviewers for their constructive comments which helped shape the final version of this essay. 
The concept of tolerance appears in early Confucian and Buddhist texts. For the generation of artists born a few decades earlier than Yang Fudong the word kuanrong is associated with Hu Yaobang's (1915-1989) leadership as General Secretary of the Communist Party from 1982 to 1987. It was used by Zhu Houze (1931-2010) Minister of the Central Propaganda Department, who in 1986 proposed the 'Three kuan Policy' of tolerance (kuanrong), leniency (kuansong) and generosity (kuanhou). ${ }^{9}$

During his time as General Secretary Hu Yaobang supported economic and political reform but was removed from office in a power struggle in 1987 owing to his laxness in stemming 'bourgeois liberalisation' or Western democratic influence following student demonstrations that erupted across the country. In the related campaign to counter the 'Three kuan Policy', Zhu Houze was demoted from the post of propaganda chief. Hu Yaobang's death a few years later in April 1989 prompted commemorative demonstrations in Tian'anmen Square, which lead to mass protests and the massacre of June 4. Yang Fudong was 18 at the time.

Responding to the hope and turmoil of the period one artist, Shen Jiawei (b. 1948), a graduate of the Central Academy of Fine Arts (1984), created an oil painting that he titled 'Tolerance' (Kuanrong). ${ }^{10}$ The painting was completed in November 1988, shortly before he left China to study in Australia. Shen Jiawei's revolutionary history paintings were highly regarded (his 1974 work 'Standing Guard for Our Great Motherland' was praised by Jiang Qing) and had been collected by the Museum of the Chinese Revolution and the National History Museum (now the National Museum of China) and the National Art Museum of China in Beijing.

Shen Jiawei is an avid reader and during the mid-1980s he procured a translation of Hendrik Willem van Loon's book Tolerance published in 1925. ${ }^{11}$ The book was translated into Chinese and published in 1936 as Kuanrong by Shanghai's Commercial Press. Like many foreign language works that were first introduced to China in the 1920s and 1930s, it was banned after 1949, and then rediscovered in the mid-1980s by a new generation of intellectuals. Van Loon's clearly articulated concepts of humanism and tolerance (religious, racial and social) outlined through parables drawn from Western intellectual history had a profound impact on Shen Jiawei.

\footnotetext{
9 'Zhongxuan yuanbu buzhang Zhu Houze zuo qushi, zeng tichu sankuan zhengce' in Dongfang zaobao, 10 May 2010. See http://news.sohu.com/20100511/n272037244.shtml; 'Zhu Houze tan kuanrong wenhua' in Fenghuang bobao 10 May 2010, see http://news.ifeng.com/history/special/mianhuaizhuhouze/content-3/ detail_2010_05/10/1500026_0.shtml (viewed 13 January 2013).

10 Shen Jiawei, n.d., 'Hua li hua wai' (Paintings: Stories Within and Beyond), unpublished manuscript. I am grateful to Shen Jiawei for providing me with a copy of this text.

11 van Loon, H. W. 1925, Tolerance, New York, Boni \& Liveright.
} 
Van Loon begins Tolerance in a storybook style: 'Happily lived Mankind in the peaceful Valley of Ignorance...' Passages that would have resonated with Shen Jiawei and Chinese youth in the late 1980s include: 'The struggle for tolerance is part of the age-old conflict between "organised society" which places the continued safety of the "group" ahead of all other considerations and those private citizens of unusual intelligence or energy who hold that such improvement as the world has thus far experienced was invariably due to the efforts of the individual and not due to the efforts of the mass (which by its very nature is distrustful of all innovations) and that therefore the rights of the individual are far more important than those of the mass. ${ }^{12}$ Ideas such as these confirmed the actions of students demonstrating on university campuses and in Tian'anmen Square, calling on the Chinese government for political reform and human rights for individuals.

In the final chapter, 'The Last Hundred Years', Van Loon concludes on an optimistic note: 'History, chary of revealing her secrets, has thus far taught us one great lesson. What the hand of man has done, the hand of man can also undo. It is a question of courage, and next to courage, of education.'13

In painting 'Tolerance' Shen Jiawei intended to commemorate the 70th anniversary of the New Culture Movement and the May 4th student demonstrations of 1919. ${ }^{14}$ Rather than focus on the usual themes of anti-imperialism and the awakening of interest in Marxism and Leninism, aroused by patriotic students protesting before Tian'an men Gate following China's treatment at the Paris Peace Conference in 1919, Shen Jiawei chose to portray leading intellectuals at Peking University associated with the New Culture Movement, individuals who promoted science, democracy and liberal values. In choosing this subject he was making a conscious link to the intellectual activities of the late 1980s, widely regarded as a continuation of the spirit of the New Culture movement.

The central figure in Shen's composition is Cai Yuanpei (1868-1940), who had studied in Germany and was President of Peking University, and former Minister of Education. Cai is surrounded by the professors and teachers he invited to teach at the University, including Chen Duxiu and Li Dazhao, who went on to found the Chinese Communist Party, the scientist and amateur photographer Liu Bannong, and the acclaimed writer and social critic Lu Xun. ${ }^{15}$ Most of the figures carry an attribute, many of them publications and texts that aid their identification. Lu Xun for example holds up the logo he designed for Peking University, which remains in use today. The two stylised archaic Chinese

\footnotetext{
12 van Loon, p. 275.

13 Ibid., p. 395.

14 Shen Jiawei, 'Hua li hua wai'.

15 Other scholars represented in the painting include Hu Shi, Huang Kan, Liang Shuming, Chen Duxiu, Li Dazhao, Liu Shipei, Qian Xuantong, Liu Bannong, Zhou Zuoren, Ma Shulun, Shen Yinmo.
} 
characters 'Bei da', literally 'Northern Great', an abbreviation of Peking Great Learning or Peking University, form a globe-like whole, at once traditional and modern.

The virtuosic generational portrait, which in its idealism and dream-like detachment has unexpected affinities with the work of Yang Fudong, as we shall see, was intended for the Seventh National Art Exhibition scheduled for June 1989. Shen Jiawei had been granted a visa to study English and left China in late 1988 the day before his visa was due to expire. The selection process for the exhibition occurred when he was in Australia. He was told by officials that the painting had not been submitted because it was larger than the specified dimensions. Two years later, the work was acquired by the National Museum of the Chinese Revolution (recommended by a friend) to fill a gap in an exhibition about the New Culture Movement of 1919. In the process of becoming an official exhibit, the title of the painting was changed from 'Tolerance' to 'The Sounding of the Bell at Peking University', attesting to ongoing sensitivity of the word tolerance. ${ }^{16}$ Located on the eastern flank of Tian'anmen Square, close to where students have historically gathered to protest, officials at the National Museum of China were careful to distance themselves from the word 'tolerance' and avoid any suggestion of forgiveness or pardon that the word might imply.

Yang Fudong was born in 1971, a generation later than Shen Jiawei, and five years before the death of Mao Zedong (1893-1976) which precipitated the end of the Great Proletarian Cultural Revolution. A painted portrait of Mao Zedong has continued Mao's watch over China, hanging below the rostrum of the Gate of Heavenly Peace at Tian'anmen Square where in 1949 he proclaimed the founding of the People's Republic of China, which became known as 'new China'. The Gate marks the entrance to the Forbidden City, former home of Chinese emperors, and epicentre of the Chinese imperial world. A closely framed portrait photograph of Yang Fudong originally included in the 'personal photo album' section of his website shows Yang standing on the edge of Tian'anmen Square, the wind blowing his fashionably long hair across his face, with the painting of Mao Zedong hovering in the background. Yang faces the camera and the Mausoleum of Mao Zedong, which was strategically placed on the imperial axis in Tian'anmen Square. The choice of a site that is so charged with socio-political significance suggests irony as well as an historical awareness that locates Yang Fudong in a specific temporal context.

Yang Fudong's family comes from Xiang He (Fragrant River), a farming village about two hours by car southeast of Beijing. He grew up in a military compound

16 Shen Jiawei, 'Hua li hua wai'. 
to the east of Beijing-an army garrison the purpose of which was to defend Beijing. ${ }^{17}$ His father was a soldier and Yang describes his life growing up in the garrison as happy, safe and free. The community was self-sufficient. It was, he said, 'a world of its own'. ${ }^{18}$

Yang Fudong moved from the world of the military compound to the world of the middle school of the elite Central Academy of Fine Arts in Beijing. He lived on campus in an enclave-like environment, a different version of the privileged, self-contained world that he had known as an army child.

After graduating from the middle school of the Central Academy of Fine Arts in 1991 Yang Fudong moved to Hangzhou and continued his studies at the China Art Academy (previously Zhejiang Academy of Fine Art). In the years since Yang Fudong's graduation from the Oil Painting Department in 1995, the Chinese art world has developed in ways that were hard to foresee.

The art academy in Hangzhou was at the forefront of the expansion of artistic practice from ink painting, oil painting, printmaking and sculpture to installation and conceptual art, performance, photography, video and new media. Zhang Peili (b. 1957), regarded as the 'father' of video art in China, graduated from the oil painting department in 1984. In 1988 he produced a video work 30x30 which records the smashing of a mirror and attempts to reassemble it with gloved hands, a process that is repeated for 32 minutes. The futility of re-assembling shattered mirror glass and reflected reality gave the work an obscure critical edge. $^{19}$

The dramatic expansion of contemporary art practice was mirrored in the proliferation of art magazines across the country and semantic shifts in magazine titles. The word meishu, which may be translated as fine art, increasingly gave way to yishu, a word that is more inclusive of a diversity of arts and contemporary practices.

Back in the late 1970s and early 1980s the Chinese art world was dominated by the magazines Art (Meishu), Chinese Art (Zhongguo meishu) and World Art (Shijie meishu) which effectively separated the Chinese world from the 'other'. As with all publications produced in China they were strictly controlled. Art was first published in 1954 and grew out of People's Art (Renmin meishu established in 1950). It is the official magazine of the Chinese Artists' Association, a national body for artists administered by the Propaganda Department of the Chinese Communist Party Central Committee (publication was suspended

17 His father belonged to an infantry unit, the Beijing Number 12 and Number 13 Public Security Regiment.

18 Claire Roberts interview with Yang Fudong, 14 January 2011.

19 In 2002 Zhang Peili was appointed to the China Art Academy to establish a new media department, which opened the following year, the first of its kind in China. 
during the Cultural Revolution and resumed in 1976). Chinese Art, produced by the Chinese Artists' Association, and World Art published by the Central Academy of Fine Arts, both appeared in 1979. World Art introduced Chinese readers to art from around the globe and was part of the project of economic liberalisation occasioned by Deng Xiaoping's 'Open door policy' after the end of the Cultural Revolution. The introduction to the inaugural issue of World Art begins: 'According to the historical experience of cultural development, a confident people should not isolate themselves from the world. In the realms of politics, economics and culture, every nation should offer their own experience to other peoples and in so doing contribute to humankind, while at the same time studying the strengths of others in order to make up for ones own deficiencies with the aim of self-strengthening'. ${ }^{20}$ By 'opening the door' China hoped to share its cultural riches with the world and get something in return, but it was clear that that something would be what the State deemed appropriate for economic development and adapted to suit China's own ends.

By the 1990s, when Yang Fudong was studying at the art academy in Hangzhou, the focus of interest had shifted from 'world art' to the 'art world' and contemporary global practice. The first Chinese magazine devoted to art as a commodity was Art and Market (Yishu shichang) published in 1991, edited by Sun Ping, Lü Peng and Zheng Shengtian (a graduate of the Hangzhou art academy and former head of the oil painting department, then based in America), and published by the Hunan Fine Arts Publishing House with the assistance of the International Institute for the Arts, USA. Information about the international commercial art world was obtained from Zheng Shengtian and a network of Chinese artists who had left China in the mid-1980s or who sought refuge overseas after the student demonstrations and massacre of 4 June 1989. The early issues of Art \& Market include reviews of overseas exhibitions and art fairs, essays on international art dealers, guidance on collecting and investing in contemporary art, legal advice on selling works of art, and a listing of commercial galleries in New York. For artists like Yang Fudong, who were studying in art academies and contemplating life after graduation, magazines like Art \& Market broadened their horizons and connected them to the international art world.

Yang Fudong's reputation as an artist with a highly refined and oblique artistic sensibility began when he was at art school. In 1993, his third year at the academy, he stopped speaking for three months and would only communicate by writing. The performance work Otherwhere: Not Speaking for Three Months was documented in photographs and video. It turned out to be a turning point in his practice. By limiting communication with the outside world he 
came to the realisation 'that it was important to have some kind of belief, some spiritual dimension to life' central to which was belief in himself as a creative practitioner. ${ }^{21}$ Yang's departure from oil painting was inspired by wide reading (including translations such as Jack Kerouac's On The Road), looking at films (such as videos of performances by Joseph Beuys) ${ }^{22}$ and the example of artistteachers and mentors including Qiu Zhijie (b. 1969) and Zhang Peili who had abandoned practice in conventional fine arts (in Qiu's case printmaking) to experiment with video, photography and multi-media arts.

A discussion of selected photographic and video works by Yang Fudong will focus on the evolution of Yang Fudong's artistic language and his resistance to conventional narrative structure. In a set of three photographs given the English title 'Don't worry, It will be better...' (2000) Yang Fudong takes the viewer into a high-rise hotel room or apartment in Shanghai. The setting is intimate but the subjects of the work (five young urbanites, four men and one woman) appear distant from one another despite their close physical proximity. While the images are like stills from a movie set their sequencing does not help to construct a plausible narrative. In the second image all five people gaze out the window of the skyscraper as if looking for an answer. Slogan-like captions in English in white on red - 'Don't worry, It will be better...' - are added to the upper right or lower left of the images recalling Communist didactic texts used to reinforce political dogma. But in this case the combination of image and text adds to our sense of bewilderment. We are not sure what is happening, and what ' $\mathrm{It}^{\prime}$ is that will be better. ${ }^{23}$

Yang uses a similar visual dynamic (incongruous pairing of image and English text) in another series of three photographs titled The First Intellectual (2000). A smartly-dressed young man who has been injured is pictured outdoors with the Pudong skyline (Shanghai's new finance and commerce hub) in the background. (At the time Yang Fudong was working in Shanghai for UBI, a French video game developer.) As with the previous work the drama that appears to have caused a brick to fall from the sky is beyond the picture frame. By removing the cause of the incident the viewer is left hanging, unable to make sense of the images or draw specific conclusions.

21 Claire Roberts interview with Yang Fudong, 28 November 2010.

22 Nesbit, M. 2011, 'Wild Shanghai Grass' in The Distance of Reality: Solo Exhibition of Yang Fudong, exh. cat., Havana, Wifredo Lam Contemporary Art Center, pp. 115-6.

23 For images of this and other works that are not illustrated see http://www.yangfudong.com/ (viewed 24 February 2013). 


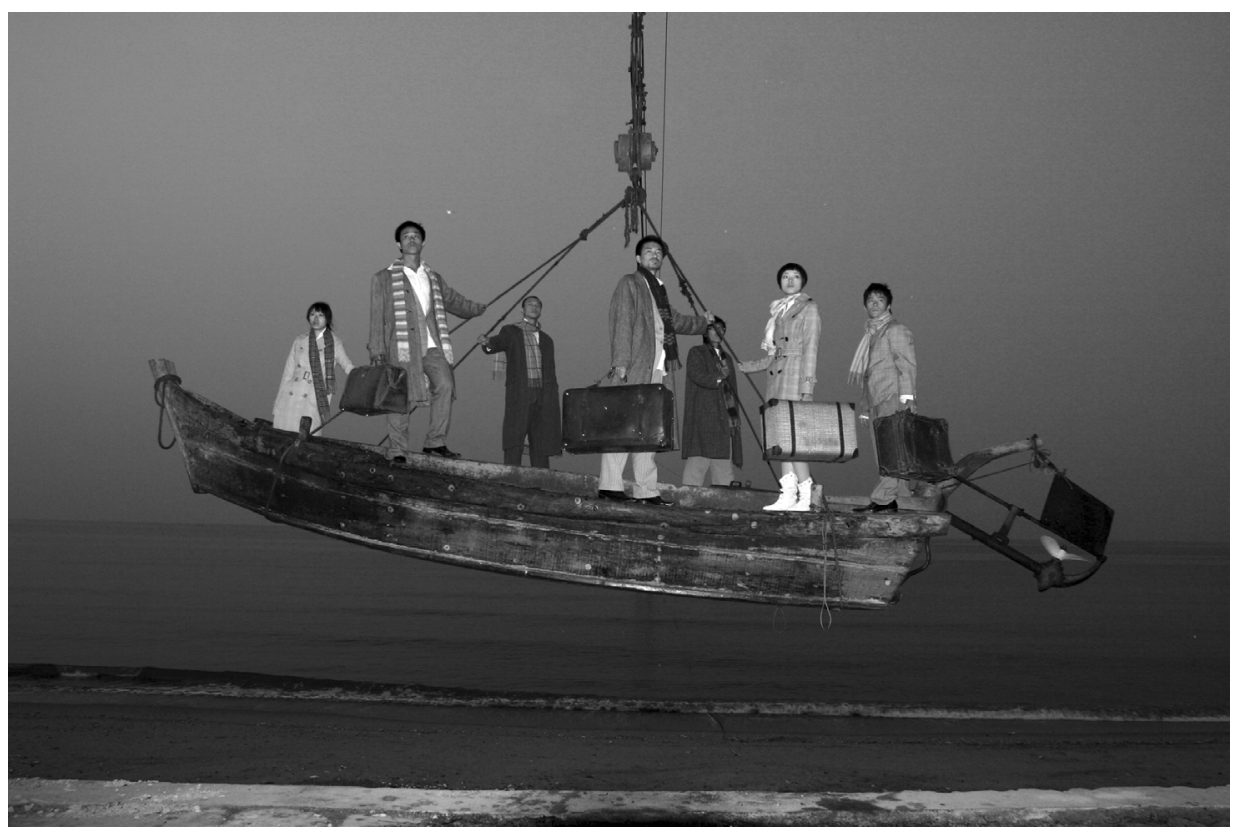

\section{Yang Fudong, 2004, Seven Intellectuals in Bamboo Forest, Part IV, Photograph B\&W C-Print, 120 x $180 \mathrm{~cm}$. Edition of 10.}

Courtesy of Artist Yang Fudong and ShanghART Gallery

Yang Fudong's most ambitious project to date and the work that brought him to international attention is Seven Intellectuals in Bamboo Forest, a five part series of black and white films that together run for some five hours that were made over five years from 2003 to 2007. ${ }^{24}$ As with previous works Yang's subject is a cohort of young people that he refers to as intellectuals.

The work was in part inspired by 'The Seven Sages of the Bamboo Grove' a group of Chinese scholars and poets of the third century who fled the chaotic and corrupt world of government service during the Three Kingdoms period (220-265) and retreated to a bamboo grove where they engaged in Daoistinspired pure thought and discussion, appreciating the beauties of nature and forgetting about worldly troubles. The 'Seven Sages' who turn their back on the official world to cultivate inner virtue have long served as a model for writers and thinkers living in troubled times.

24 Yang Fudong: Seven Intellectuals in Bamboo Forest, 2008, exhib. cat. Stockholm, Jarla Partilager. The first instalment of the five-part work was shown at the Venice Biennale in 2003 and the entire cycle was shown at the Venice Biennale in 2007. 
Yang Fudong's series opens with the seven 'young intellectuals' in the mountainous landscape of Huangshan or Yellow Mountain, described by Yang as 'A postcard-like set of travel notes on the good life'. Part Two locates the group in 'a flourishing city'. Part Three finds them in the countryside where they plough by day and rest by night 'forgetting all that bothers them'. In Part Four they are on an island described by Yang as 'a tiny island of belief' that might be utopia; and in Part Five they 'return to the city, devoid of identity', still a collective of youth, but their future uncertain. ${ }^{25}$ Yang's brief descriptions, like the films, suggest a quest for utopia that is ultimately not realised.

The five parts, screened simultaneously, explore ideas related to history and memory, myth and reality. They use visual and sensory means to give form to things that have no form and are difficult to express. While Chinese history as well as natural, regional and urban landscapes form backdrops to the films, narrative disjunction and a haunting visual beauty cause viewers to lose their bearings in time and space.

Under Mao Zedong Chinese society was turned on its head. In the project to create a socialist utopia the former ruling class, largely made up of intellectuals and considered politically suspect were purged and less educated classes workers, peasants and soldiers - rose to prominence. The parallels between 'Seven Intellectuals', 'Seven Sages' and the experiences of rusticated youths, urban intellectuals who during the Cultural Revolution were sent to the countryside to learn from illiterate farmers, suggest an allusive commentary on the plight of independent-minded intellectuals and the extreme experiences to which young people were subjected in the recent past. Here, the incongruity of earlier English language titles previously noted is replaced by a 'Chinglish' rendition of the generally accepted English translation of Zhu lin qi xian (The Seven Sages of the Bamboo Grove), the Chinese title of the work highlighting the agency of the artist. $^{26}$

In No Snow on the Broken Bridge (2006) Yang Fudong continues to reflect on word play and the lives and minds of a group of young people. Like his earlier film An Estranged Paradise (2002), it was filmed in Hangzhou, an ancient capital famous for the West Lake, and historically regarded as 'Paradise on Earth'. It was where Yang Fudong went to art school, a place that he 'loved'. 'It was,' he said,' where I grew up'. ${ }^{27}$ 


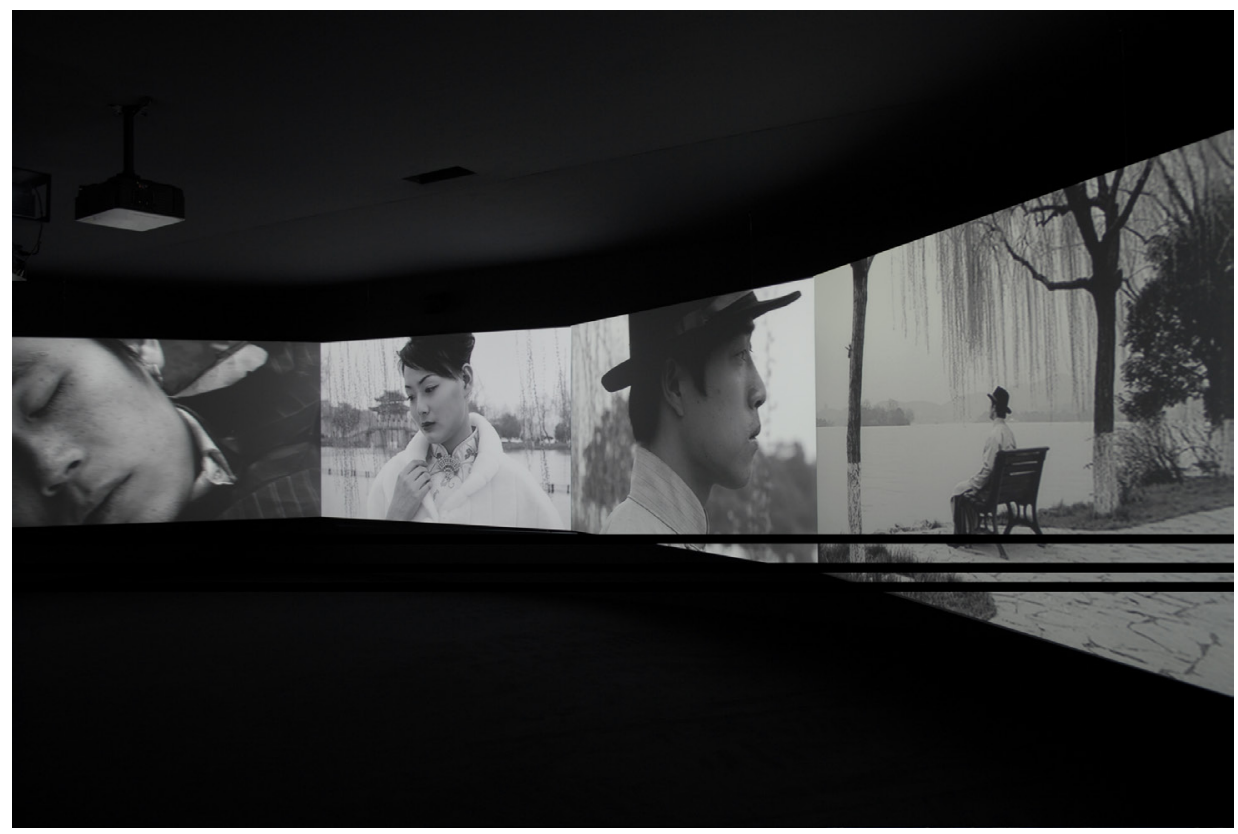

Yang Fudong, 2006, No Snow on the Broken Bridge, Installation view in Parasol Unit, London. 8-channel video installation, $35 \mathrm{~mm}$ b\&w film transferred to DVD, music by Jin Wang, 11 minutes. Edition of 6 .

Courtesy of Artist Yang Fudong and ShanghART Gallery

The title of Yang's work No Snow on the Broken Bridge refers to the phrase 'Lingering Snow on the Broken Bridge' (Duan qiao can xue) one of the acknowledged 'Ten Famous Views of the West Lake'. The historic Duan Family Bridge is located on the eastern end of the Bai Causeway at the West Lake in Hangzhou. Duan is a surname, but a different Chinese character with the same pronunciation means 'broken'. While the bridge is thought to date from prior to the seventh century, the poetic scene that it evokes dates from the time Hangzhou was the capital of the Southern Song Dynasty (1127-1279). The snow-clad landscape and dark lake evoke the beauty of crystal and jade, or a brush-and-ink painting. A tourist plaque erected at the site describes the scene: 'Standing on top of Baoshi Hill, one can have a bird's eye view of the beautiful scenery to the south: Bai Causeway lying beneath a blanket of snow looks like a long silver chain across the lake, which seems to break up abruptly when it reaches the end of the causeway, where the dark surface of the bridge emerges from the melting snow, evoking the magical scene of the 'bridge breaking as the snow melts'.' The phrase canxue, or 'lingering snow', may also be translated as 'the dirty snow that refuses to melt', implying a relentless kind of melancholy. The site is also associated with the 'Legend of the White Snake', a popular 
folktale about a white snake that took the form of a beautiful girl who falls tragically in love with a young man. Yang Fudong mines the poetic richness of the subject, allowing viewers to bring a range of associations to his work.

Men wearing long robes and women wearing cheong sam (qipao) promenade and linger in pairs or foursomes, exploring the environment and their inner selves. They are travellers who come with expectations, but it is hard to predict what their futures might hold. A mountain goat is led on a leash, and a cockatoo is tethered to a carrying frame, suggesting the subservience of animals and birds to humans who desire to treat them as objects of curiosity or aesthetic pleasure.

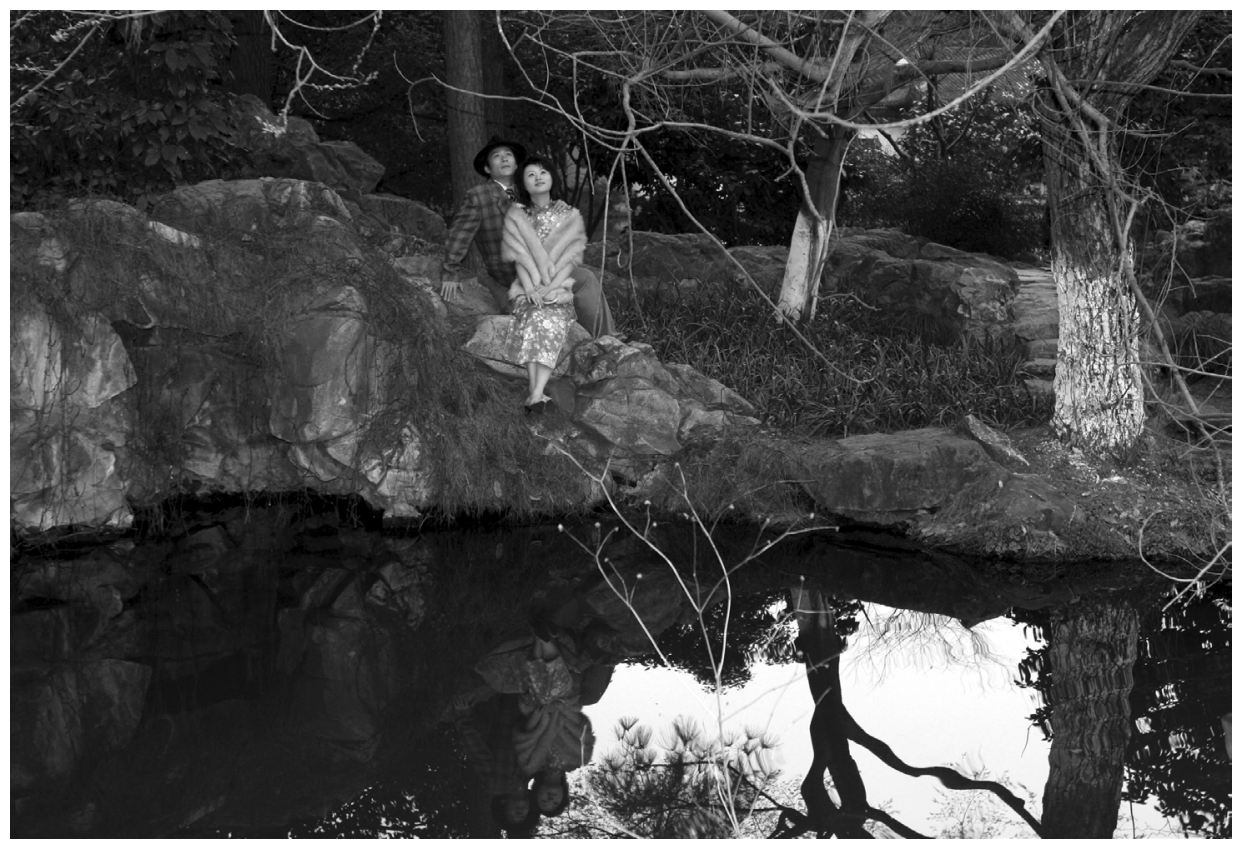

\section{Yang Fudong, 2006, No Snow on the Broken Bridge-11, Photograph B\&W C-Print, $120 \times 180 \mathrm{~cm}$. Edition of 10 .}

Courtesy of Artist Yang Fudong and ShanghART Gallery

Yang Fudong 's imagery evokes the feeling of snowfall that remains after it has stopped snowing, which he describes as being the 'like the beauty of an ice maiden.' ${ }^{28}$ The feeling is he says 'very beautiful, but it is imbued with an air of tragedy'. ${ }^{29}$ Visually seductive images are projected onto eight large screens immersing the viewer in a familiar yet unfamiliar world of Yang Fudong's making; of interconnected narratives without beginning or end. The viewer is invited to engage freely with the films (there is no expectation that the films are

28 Claire Roberts interview with Yang Fudong, 14 January 2011.

29 Claire Roberts interview with Yang Fudong, 28 November 2010. 
seen in sequence or from start to finish) and by viewing imagery on different screens create their own free-form film (ziyou dianying). Like other works that have been discussed, the structure and artistic language of 'No Snow' prevents any single or simple interpretation. The work is open and opaque, defiant in its inability to fix meaning.

Yang Fudong's photographs and films are about moods and emotions, escape and entrapment, truth and deception. The language is cool and yet he seeks to plumb emotional depths, drawing strength from deeply felt aspects of life and culture. Yang Fudong is not overwhelmed by China's visual past, seeing it as a complex language that continues to evolve, and to which he is connected. He begins An Estranged Paradise with a lesson on Chinese brush-and-ink painting. The hand of an artist creates a landscape painting and a narrator explains (with English subtitles): 'Poetic mood is the life of painting...But how can poetic mood be achieved?...'

Yang Fudong admires the modern brush-and-ink painter Fu Baoshi (1905-1965), a cosmopolitan artist-intellectual (he studied in Japan in the early 1930s and was part of an official delegation of artists that travelled to Czechoslovakia and Romania in 1957) who lived during a turbulent period of war and revolution: 'He is a great contemporary figure painter. He did something different. With his figures painted in an antique mode he moved things forward a lot. He is a bit like a modern Liang Kai (active first half of the 13th century) ${ }^{30}$ who painted figures using a splashed ink technique. His paintings are beautiful, including his landscapes.... He is like a hot-blooded youth. His paintings give you a feeling of the extraordinary. ${ }^{31}$

Fu Baoshi's paintings of historic and mythic beauties-the Goddess of the Xiang River, mountain spirits, or of beautiful women inspired by the paintings of Gu Kaizhi (ca. 345-406), with their clear, flowing lines and depiction of atmospherics (branches of pine and willow trees blown by the wind; swirling autumnal leaves) and harmonious brush-and-ink technique (fine calligraphic lines; moody ink wash; delicate colours) are imbued with a poignant beauty, a poetic mood that resonates with the aesthetic sensibility found in No Snow on the Broken Bridge. ${ }^{32}$

Fu Baoshi painted several versions of Seven Sages of the Bamboo Grove between 1943-45, the Sino-Japanese war period. In each case the figures occupy their own space as they drink wine, play the zither, view paintings and commune with nature, highlighting their significance as individual men of conscience.

30 Liang Kai is a Southern Song (1127-1279) artist who lived and worked near Hangzhou, renowned for his spontaneous, abbreviated painting style.

31 Claire Roberts interview with Yang Fudong, 28 November 2010.

32 Chung, A. 2012, Chinese Art in an Age of Revolution: Fu Baoshi (1904-1965), exhib, cat., New Haven, Yale University Press, pp. 20, 105, 183. The Goddess or Lady of the Xiang River is a subject in the Nine Songs (Jiu $g e)$, poems that are traditionally attributed to Qu Yuan (343-278 BCE). 
In painting this subject $\mathrm{Fu}$ Baoshi was perhaps alluding to gatherings of likeminded friends who sought solace in one another's company in Chongqing, the wartime capital of the Republic of China during the Sino-Japanese war. ${ }^{33}$ As in the painting by Fu Baoshi, Yang Fudong's Seven Intellectuals also occupy a common pictorial space and yet are remote from one another, suggesting a similar interest in the idea of retreat from worldly trouble.

After finishing Seven Intellectuals there was a change in Yang Fudong's artistic style. Works such as East of Que Village (2007) and Blue Kylin (2008) depict places and the activities of people and animals that are real. Acknowledging the shift to a straighter documentary-like style Yang observed: 'I could no longer make films with that Utopian feeling, or with what some have described as a formalist style' ${ }^{34}$

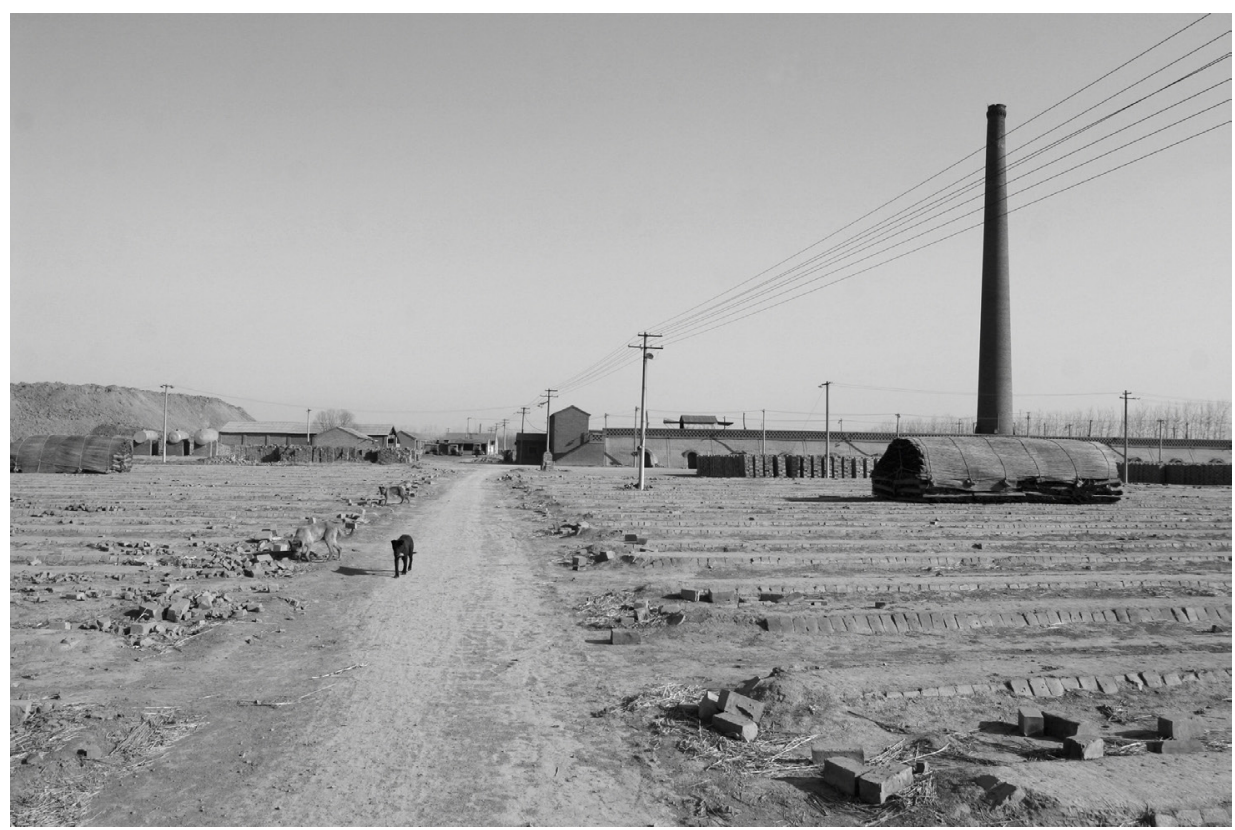

\section{Yang Fudong, 2007, East of Que Village, Still from 6-channel video installation, HDV, 20 minutes 50 seconds. Edition of 6.}

\section{Courtesy of Artist Yang Fudong and ShanghART Gallery}

Filmed in a village close to where his grandparents lived and not far from where he grew up, East of Que Village reflects Yang's desire 'to capture a feeling of the north' associated with his youth: a feeling of extreme cold, dry atmosphere and bare trees. Dogs feature prominently in the film. 'They look like wild dogs,' he 
says, 'and yet they cannot leave the village...They depend on people to eke out life...When I was growing up, these dogs left a deep impression on me. They were aggressive and scary but they were also prone to dying in winter. ${ }^{35}$

In China, as elsewhere, truth is often stranger than fiction. Yang Fudong is one of many photographers and filmmakers who have focused their lens on the real world and presented it as art. The documentary turn, which began in the late 1980s, has been a powerful trend enabling experimental artists to give expression to humanitarian ideals. For Yang Fudong it is perhaps a way of returning to first principles, using his own eyes, mind and visual poetry to record something of the complex and contradictory world of contemporary China, a world in which it is still possible to discover haunting beauty and chilling terror.

When the National Museum of China re-opened to the public in its refurbished and expanded form in 2011, Shen Jiawei's painting 'Tolerance' was included in the permanent exhibition 'The Road of Rejuvenation' (Fuxing zhi lu), a major display chronicling the story of China's rise from the humiliation of the Opium Wars of the 1840s to the present. ${ }^{36}$ The painting hangs in a section of the exhibition devoted to the New Culture Movement, displayed with a bilingual label and the titles 'Jian rong bing bao' and 'Inclusiveness' rather than Shen Jiawei's original title 'Tolerance' (Kuanrong). Jian rong bing bao is an historical phrase used by Cai Yuanpei to describe his approach to building a new educational culture at Peking University. The phrase means to unite or come together in an acceptance of inclusiveness and has come to be associated with Cai Yuanpei and his philosophy of bringing together academics from different spheres in the interests of creating a research culture at the university. In an essay published in 1937 Cai Yuanpei observed: 'following freedom of thinking (sixiang ziyou) leads to inclusivity (jian rong bing bao)'. ${ }^{37}$ The phrase 'Jian rong bing bao' (without the reference to free thought) was deemed more acceptable than kuanrong which is associated with 1980s liberalisation and has a broader connotation in relation to human behaviour.

35 Claire Roberts interview with Yang Fudong, 14 January 2011.

36 See http://en.chnmuseum.cn/tabid/520/Default.aspx?ExhibitionLanguageID=83 viewed 24 February 2013.

37 Cai Yuanpei, 1937, 'Wo zai jiaoyu jie de jingyan' in Gao Pingshu (ed.), Cai Yuanpei jiaoyu wenxuan, Beijing, Renmin jiaoyu chubanshe, 1980, p. 244. 


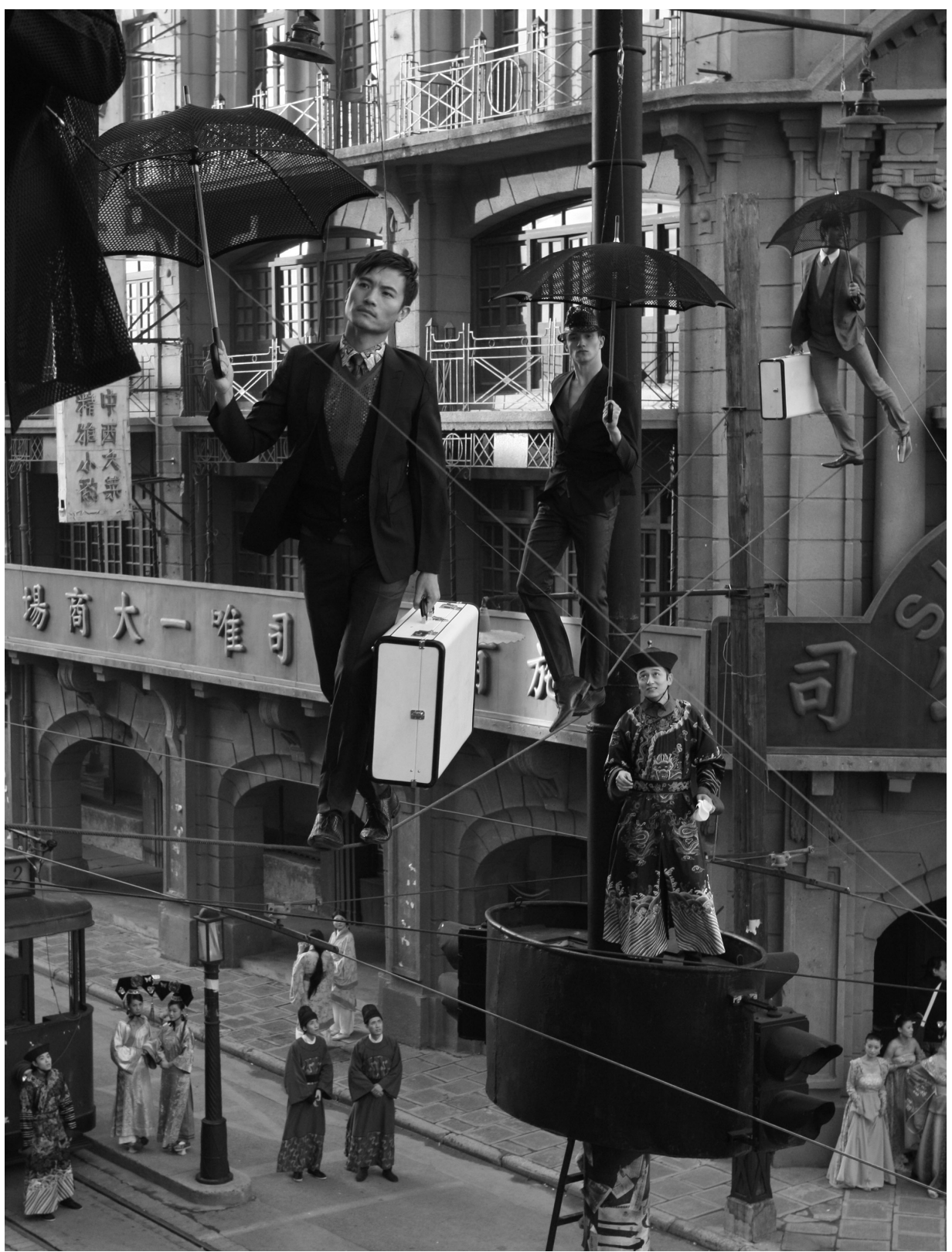

Yang Fudong, 2010, First Spring, Single-channel video (Art Project Cooperation with PRADA), 9 minutes 11 seconds.

Courtesy of Artist Yang Fudong and ShanghART Gallery 
The National Museum of China with close to 200,000 square metres of exhibition space claims to be the 'largest museum in the world with first class facilities and capabilities'. ${ }^{38}$ It has a focus on history and art and a growing interest in international exchange and loan exhibitions. Soon after re-opening in 2011 the museum staged Louis Vuitton: Voyages, an historical survey of the luxury brand of suitcases and bags celebrating the art of travel. Louis Vuitton has stores in more than 29 Chinese cities from Beijing to Urumqi, and in 2012 celebrated 20 years of doing business there. Using hot air balloons as a display device, exhibition designers sought to focus on the history and romance of global travel. The exhibition attracted considerable controversy, with visitors and museum professionals questioning the decision by the national museum to showcase commercial products through an historicised narrative (the company was established in 1854). ${ }^{39}$ This and other exhibitions are striking examples of the kind of commercially driven projects that have been staged in China's new first class state facilities, underlining the dramatic changes that have occurred in Chinese society over the past 30 years.

An installation by contemporary Chinese artist Zhan Wang provided a dramatic introduction to the Louis Vuitton exhibition, further highlighting the increasingly blurred boundaries between art, business and state-funded cultural enterprise. ${ }^{40}$ 'My Universe: The Beginning ', a personalised meditation on the 'Big Bang', involved six high definition video projections of the detonation of a huge boulder, and the installation of fragments of the exploded boulder recreated in Zhan Wang's signature stainless steel which were suspended on fine wires in the gallery space. The artist's ambition in attempting to recreate the birth of the universe resonated with the sensory experience of visiting the National Museum of China, its vast entry hall and gallery spaces emphatically defying human scale.

Like Zhan Wang, Yang Fudong is not averse to lending his image to a luxury brand. In 2010 he was invited by Prada to direct a short film to launch its Spring/ Summer menswear collection. Prada, like Louis Vuitton, has an important market in China and Yang Fudong's film was presumably intended to attract a new image-conscious art-savvy clientele. ${ }^{41}$ Shot in a film lot against a backdrop of faux 'old Shanghai' buildings and trolley buses, Prada-clad men combine with Chinese models in ancient dress to create what has been described as a 'timeless,

38 See http://en.chnmuseum.cn/english/tabid/497/Default.aspx (viewed 24 February 2013).

39 See http://en.chnmuseum.cn/tabid/520/Default.aspx?ExhibitionLanguageID=79 (viewed 13 January 2013). Bvlgari: 125 Years of Italian Magnificence an exhibition about the history of the luxury jewellery brand Bvlgari was held in September-November 2011 and was equally controversial. See http://www.globaltimes. cn/NEWS/tabid/99/ID/675301/National-Museum-of-China-under-fire-again.aspx (viewed 13 January 2013).

40 See http://www.zootmagazine.com/2011/06/03/louis-vuitton-voyages-at-the-national-museum-of-china/ (viewed 24 February 2013).

41 See Yang Fudong, First Spring https://www.youtube.com/watch?v=nhswOlqbPUU (viewed 13 January 2013). 
dreamlike realm where anything is possible. ${ }^{42}$ Titled First Spring, alluding to earlier works associated with young intellectuals and the flowering of youth (though not in any way comparable, and unconvincing as a work), the video contains scenes of fashionably dressed men walking on wires above the city with their security apparatus and means of production visible. For Yang Fudong this is a conscious device that highlights 'the real and the reality of the film'. 'All the false impressions' he says 'are meant to happen in the film studio'. ${ }^{43}$ In an interview with Li Zhenhua in 2010, Yang Fudong recalls an early experience working as deputy art director on a film shoot that involved a Western church that had been converted into a primary school (as was the case in the Republican and later periods). Within the church he re-created classrooms from different periods so that the shooting could happen quickly. One day a strong beam of sunlight projected through the clouds after heavy rain illuminating a wall of the classroom and brought the set to life. 'It was so fake' he said, but felt 'so real!' ${ }^{44}$

In contemporary China it is increasingly difficult to distinguish what is real and what is fake or 'new antique'. In the case of First Spring, where Yang Fudong's ongoing play with questions of reality is directed towards purely commercial ends, we might well ask Yang Fudong 'What is the reality in your mind?' Here Yang Fudong's artistic activity and definition of tolerance extends to lending his name to a luxury global brand. In China the international art market has an increasingly powerful reach and the allure of working with large budgets and luxury brands that cater to a broader global audience is difficult for some artists to resist. The exposure and social prestige that Yang Fudong may have gained through First Spring must however be set against the diminution of his image as an independent artist, a status that in China is hard won. With the blurring of boundaries in China's Communist controlled, state capitalist economy in which international luxury brands flourish, the world of Yang Fudong is very different from the world of Shen Jiawei. Shen Jiawei enthusiastically painted propaganda art during the Cultural Revolution and created the painting 'Tolerance' as a way of forging his own version of history painting, a style that might be described as critical realism. Shen Jiawei is of an older generation and one for whom the word 'tolerance' has a specific meaning that is closely tied to the social-politics of the late 1980s. Yang Fudong's understanding of the word is more nuanced and not tied to a particular historical moment, reflecting perhaps the uncertainty and cultural flux that characterises contemporary Chinese society as a whole.

42 See http://www.justluxe.com/luxe-insider/trends/feature-300994.php (viewed 22 April 2013).

43 Li Zhenhua, 'Do Human Beings have Spiritual Life?', p. 165.

44 Ibid., pp. 165, 177-8. 